\section{RECIFES ARTIFICIAIS E SUA IMPORTÂNCIA PARA O TURISMO NAS REGIÕES COSTEIRAS MARINHAS}

\author{
Luiz Roberto Tommasi*
}

RESUMO: O homem tem utilizado, com frequiência, os recursos renováveis costeiros de forma conflitante com sua conservação. Isso tem ocorrido devido à destruição de habitats, de suas funçōes ecológicas e da redução da sua biodiversidade, inclusive por poluição. Visando recuperar áreas costeiras empobrecidas, têm sido instalados recifes artificiais construídos com uma grande variedade de materiais e restos de embarcaçōes. Isso tem levado a um aumento da fauna incrustante e de peixes, com interessantes reflexos sobre os setores náutico, hoteleiro e turístico de um modo geral. São apresentados alguns procedimentos básicos a uma correta implantação de recifes costeiros artificiais em nosso País.

UNITERMOS: Turismo: areas costeiras: recifes artificiais. Recifes artificiais: turismo náutico; turismo.

ABSTRACT: The man has been used with frequency, coastal renewable resources in a way which is in conflict with its consen ation. This has occurred due to the destruction of the habitats, its ecological function, and to the reduction of its biodiversity, including pollution. Aiming to recovery impoverished coastal areas, artificial reefs has been constructed using a varien ot materials and residues ot vessels. This has becn induced the growth of fouling and fishes, with interesting reflex, in a general manner, on nautical and tourist areas. Some basic procedures to a correct implantation of artificial coastal reefs in our country are presented.

KEY WORDS: Tourism: coastal areas; artificial reefs. Artificial recfs: nautical tourism; tourism.

$\left(^{*}\right)$ Professor Titular do Departamento de Oceanografia Biológica. Diretor do Instituto Oceanográfico da USP.

End. para corresp.: Cidade Universitária "Armando de Salles Oliveira" - Pça. do Oceanográfico, 191 - CEP 05508 - 900 - São Paulo - SP - Brasil.

\section{INTRODUÇÃO}

Como mostra Diegues ${ }^{1}$, os conceitos de planejamento, gerenciamento, manejo e administração de recursos naturais dizem respeito a técnicas e modos pelos quais se obtém um desenvolvimento integrado e auto-sustentado. São, portanto, condições necessárias ao desenvolvimento, à superação dos obstáculos e não fins em si mesmo.

Os ecossistemas costeiros apresentam inúmeros usos ao homem, que podem ser complementares, conflitantes ou mutuamente exclusivos. Entre esses estão tanto a pesca, a agricultura, a pesca esportiva, o turismo ecológico, como também o lançamento de poluentes, a especulação imobiliária, a construção de portos e de marinas mal planejadas, impactantes etc.

O turismo, potencialmente, pode induzir diversos tipos de impactos negativos sobre variáveis ambientais como: penetração da luz na água do mar, em função da quantidade de material particulado na mesma, cor da água do mar, temperatura, sais nutrientes, metais pesados, microrganismos causadores de doenças de origem fecal, biodiversidade, produtividade primária, assoreamento etc. Deve-se destacar, ainda, a incrível mania que muitos têm de colocar datas, nomes, mensagens, corações etc., em sítios e monumentos históricos, ou, então, levar "recordações" dos mesmos.

\section{RECIFES ARTIFICIAIS E $\odot$ TURISMO}

Um dos meios que tem recebido grande atenção para o desenvolvimento do turismo, especificamente no âmbito da pesca esportiva nas regiōes costeiras, é a construção de recifes artificiais, que bem planejados e executados nada poluem, nada impactam. Pelo contrário, passam a se constituir em fator relevante de desenvolvimento daquele sistema.

O objetivo fundamental é construir um sistema que contribua para atividades recreacionais dos turistas. Assim, os recifes artificiais somente deverão ser construídos, onde possam ser usados efetivamente para a pesca esportiva, para mergulhos turísticos monitorados de observação da vida marinha e para pesquisas científicas.

Devido a isso, não adianta colocá-los onde não existam ilhas, rochas submersas, recifes de coral etc., que possam agir como fonte de espécies que irão povoá-los. Se essas fontes existirem, os recifes poderão se constituir em novos viveiros de peixes, lagostas, de rica incrustaçāo biológica ("fouling"), com inúmeros e efetivos atrativos. 
A sua construção e manutenção só é possível com o apoio de uma equipe multidisciplinar, pois envolve aspectos ecológicos, geológicos, oceanográficos, pesqueiros e legais. Assim, por exemplo, após a instalação do recife artificial, tem-se que mantê-lo por certo tempo proibido à pesca, para permitir a instalação, no mesmo, de uma fauna e flora. Tem-se, ainda, que integrá-lo aos programas turísticos locais, criar um sistema de apoio a visitas e vigilância para evitar abusos, pesca predatória e poluição.

O ideal seria a existência de um projeto a nível nacional, envolvendo a instalação de recifes artificiais pilotos no nordeste, no sudoeste e no sul do Brasil. Em cada um desses locais deveriam, claramente, ser definidos os objetivos dos recifes artificiais, como, por exemplo: aumentar a produção pesqueira de peixes de pedras e costões; aumentar as atrações turísticas locais; criar centros de pesquisas científicas marinhas etc.

O importante é a identificação de efetivas condições de acompanhamento da qualidade da água, das condições da fauna e flora que crescerão nos recifes artificiais, bem como do uso pelos turistas e pescadores dos mesmos. Caso contrário, estar-se-á apenas despejando materiais no oceano sem qualquer outro objetivo.

Os locais para construção dos recifes devem ser escolhidos com o máximo cuidado, face aos riscos para a navegação e pesca, e possibilidade de induzirem assoreamento e de influenciarem na circulação local do mar etc. Devem ser locais de acesso fácil, sem riscos para as embarcações e os turistas.

São fatores relevantes o tipo de material empregado na sua construção, a profundidade local e sua acessibilidade a todos os tipos de turistas. Deve-se considerar se o recife poderá oferecer perigos aos mergulhadores, que vão desde o ataque de moréias e tubarões, até ferimentos. É importante divulgar informações aos turistas para evitar tais perigos e como proceder se ocorrerrem acidentes e ataques daqueles peixes.

Nos Estados Unidos foram identificados conflitos em relação à construção de recifes artificiais, relacionados ao uso dos mesmos por mergulhadores e pescadores. A presença de um desses grupos cria problemas diversos ao outro. Há conflitos entre pescadores comerciais e recreacionais.

Por isso tudo, antes mesmo de se iniciar, a nível nacional, um programa de construção de recifes artificiais, é necessário estabelecer uma legislação a respeito, identificar os órgãos Federais, Estaduais e Municipais que se encarregarão dos mesmos.
Um bom exemplo, é o "National Artificial Reef Plan" (1985) do NOAA - National Oceanic and Atmosphere Administration ${ }^{2}$, dos Estados Unidos, que poderia servir de base para a instalação de um programa nacional similar. Entre as questões de natureza científica que devem ser abordadas num projeto de construção de recifes artificiais, esse órgão menciona, entre outras, as destacadas a seguir.

a) Qual é a relação entre atração e produção de funções nos recifes artificiais, para várias espécies de peixes, sob várias condições oceanográficas?

b) Os recifes artificiais podem, efetivamente, ser fatores de mitigação, por exemplo, substituir habitats perdidos? Em que condiçōes isso seria possível? Têm potencial para o desenvolvimento da maricultura (criação de peixes, mariscos e outros animais marinhos)?

c) Que tamanho deve ter um recife artificial para sustentar uma dada pressão de pesca?

d) Quais são os benefícios de projetar, construir e implantar recifes artificiais, ao recrutamento, crescimento e desova de peixes, crustáceos etc.?

e) Como se deve gerenciar um recife artificial, para que o mesmo venha a possuir comunidades marinhas de efetivo interesse turístico?

f) Todas as regiões costeiras brasileiras oferecem condições favoráveis à implantação de recifes artificiais?

\section{CONSIDERAÇÕES FINAIS}

O uso de recifes artificiais é hoje uma realidade, ainda que existam grandes diferenças, por exemplo, entre os Estados Unidos e o Japão. No primeiro, a maioria desses recifes são grandes, de baixo custo, construídos com refugos e em águas profundas de plataforma continental. Visam, especialmente, a pesca esportiva com embarcações. Já no Japão, são construídos por engenheiros, com materiais duráveis, pre-fabricados e colocados em locais cientificamente escolhidos, tanto em águas rasas como profundas. Visam, primariamente, o uso pelos pescadores comerciais ${ }^{3}$.

Essas estruturas têm permitido um efetivo aumento da pesca, pela concentração de peixes que induzem e pelo aumento da produção natural dos recursos biológicos marinhos. Há estudos mostrando que logo após a instalação dos recifes, eles são recobertos de algas, ostras, caramujos, ouriços do mar, algas etc. ${ }^{\dagger}$ Os peixes também colonizam rapidamente os recifes ${ }^{5}$ e atingem densidade máxima dentro de alguns meses após a instalação dos mesmos ${ }^{6}$. Prince ${ }^{7}$ elaborou um modelo preliminar da cadeia alimentar que se instala nos recifes artificiais. 
É importante a observação de Buckley ${ }^{8}$ de que os peixes migratórios são mais importantes nos recifes artificiais, do que os residentes, representando até $67,4 \%$ da pesca em recifes com dois anos de idade.

Como apontam Bohnsack e Sutherland ${ }^{3}$, os recifes artificiais se transformam numa técnica muito popular de criação de novos habitats costeiros e de estímulo à pesca recreacional e mesmo comercial.

Especificamente no Brasil, se forem bem planejados e implantados serão, sem dúvida, mais um relevante atrativo turístico na região costeira, competindo, com sucesso, com outros projetos recreacionais, aos quais acabarão se entrosando e fazendo parte efetiva. São, também, um fator de desenvolvimento da indústria e do comércio de materiais náuticos (barcos, equipamentos de pesca e de mergulho), de empregos naqueles dois setores da economia e, ainda, uma interessante oportunidade profissional para biólogos, ecólogos, como, inclusive, monitores e guias turísticos.

\section{REFERENCIAS BIBLIOGRÁFICAS}

1. DIEGUES, A. C. Planejamento e gerenciamento costeiro - Alguns aspectos metodológicos. Encontro Nacional de Estudos sobre Mcio Ambiente. 1989. Anais. Florian6polis, UFSC, 1989, v. 3, p. 112-150.

2. NATIONAL OCEANIC AND ATMOSPHERIC ADMINISTRATION NOAA NATIONAI, MARINE FISHERIES. Service, Washington, DC, p. 3.9. (NOAA Tech. Mem. NMFS OF-06).

3. BOHNSACK J. A. \& SUTHERLAND, D. L. Artificial reef research: a review with recommendations for future priorities. Bull. Mar. Sc. 1985, v. 37, n. 1. p. 11-39.

4. MOTTET, G. M. Enchancement of the marine environment for fisheries and aquaculture in Japan. Wash. Dep). Fish., 1981, 96 p. (Tech. Rep., 69).

5. BOHNSACK, J. A. \& TALBOT, F. H. Species - packing by reef fishes on Australian and Caribbean reefs: an experimental approach. Bull. Mar. Sc., 1980, n. 30. p. 710-23.

6. STONE, R. B. et al. A comparison of fish populations on an artificial and natural reef in the Florida Keys. Mar. Fish. Re1: 1979, v. 41, n. 9, p. 1-11.

7. PRINCE, E. D. et al. Trophic dynamics of a freshwater artificial tire reefs. In: CLEP. PER, H. Predator-prey systems in fisheries management. Washington. Sport Fishing Institute, 1976, p. 459-73.

8. BUCKLEY, R. M. Marine habitat enchancement and urban recreational fishing in Washington. Mar. Fish. Rev.. 1982, v. 44, n. 6-7, p. 28-37. 